\title{
Conservation Strategies for Local Breed Biodiversity
}

\author{
D. Phillip Sponenberg ${ }^{1, *}$, Alison Martin ${ }^{2}$, Charlene Couch ${ }^{2}$ and Jeannette Beranger ${ }^{2}$ \\ 1 Virginia-Maryland College of Veterinary Medicine, Virginia Tech, Blacksburg, VA 24061, USA \\ 2 The Livestock Conservancy, P.O. Box 477, Pittsboro, NC 27312, USA; \\ amartin@livestockconservancy.org (A.M.); ccouch@livestockconservancy.org (C.C.); \\ jberanger@livestockconservancy.org (J.B.) \\ * Correspondence: dpsponen@vt.edu; Tel.: +1-540-231-4805
}

Received: 9 September 2019; Accepted: 25 September 2019; Published: 27 September 2019

check for updates

\begin{abstract}
Breeds of domesticated animals are often overlooked as contributing to biodiversity. Their unique role at the junction of natural and human-influenced environments makes them important potential contributors to biodiversity and ecosystem function. Effective conservation of livestock breeds rests upon valid recognition of breeds as repeatable genomic packages with a reasonably high level of predictability for performance. Local or landrace breeds that lack breeder organization are especially difficult to conserve due to lack of formal recognition as breeds. Achieving success with them involves three major steps: Discover, Secure, and Sustain. Early in the process an evaluation of candidate populations for status as genetic resources is essential. This process is aided by a phenotypic matrix which can be used alongside historical investigations and genetic (DNA) studies. The goal is to include all qualifying animals and to exclude all those that do not qualify. Securing some populations depends on careful rescue protocols for maximizing the recovery of genetic variation, and this can then be followed by breeding protocols that provide for maintaining the population's production potential along with a healthy and viable genetic structure for long-term survival and use. Sustaining breeds for the long term is also enabled by assuring market demand for the breed and its products.
\end{abstract}

Keywords: livestock; breed; conservation

\section{Introduction}

Domesticated animals occupy a unique niche that depends on both natural and direct human influences [1]. This is especially true of those animals that are used in agricultural systems in which both biological and production goals combine in ways that are distinct from the selection environments of wild biota. As a result successful breed conservation needs to include attention to biological, production, and cultural aspects that affect these populations. All three aspects must be considered if success is to be achieved in adequately conserving genetic resources of domesticated animals, and failure in any one dimension often leads to overall failure [2]. Breed conservation has gained importance over the last few decades due to increased recognition that the biodiversity housed in domesticated animals is key to maintaining overall biodiversity [3]. Breed conservation is especially important for those species whose wild ancestors are now extinct (cattle, horses, camels), because these lack any other source of biodiversity that can be used in maintaining their function in certain environments [2].

"Breed" has varying definitions, some very loose and others very strict [2,3]. At the core of the usefulness of the breed concept is a reasonably high degree of predictability across animals in a designated group, for some desired production or behavioral output. It is predictability that gives breeds their utility because a breed can then be chosen reasonably accurately to fulfill specific goals. A concept of "breed" that addresses this issue is generally the most practical. Maintaining breed utility 
is a compromise between the genetic uniformity that leads to a high degree of predictive accuracy, and the opposing need for genetic variability that is required for a population's biological viability.

Breeds are subpopulations of domesticated animals that derive their uniformity from a combination of foundation events, followed by isolation and selection [2]. The foundation of a population constrains the eventual range of genotypes possible in that population, and has often been more an accident of history than the result of a careful and deliberate decision-making process. This somewhat haphazard history has the advantage of providing pockets of rare and distinctive genotypes in various locations worldwide. These are worthwhile as targets of conservation programs due to their maintenance of otherwise rare genetic signatures. Examples include the Buša cattle of the Balkans [4], Criollo Cattle of the Americas [5], the Estonian Native horse [6], and several other locally rare breeds.

After foundation, isolation from repeated genetic introgression helps to assure a population's genetic distinctiveness [2]. The opposite situation involves repeated introgression from a variety of sources and results in genetically mixed populations that lack the uniformity so essential to prediction of function for both environmental adaptation and production parameters.

Selection works on isolated populations of unique foundations to yield the final breed that fits well with certain specific environments and production goals. Selection includes influences imposed by natural environments as well as by human owners. This is different from the more strictly natural selection environment experienced by wild species.

When "breed" is used in the sense of a reasonably uniform genetic resource, then it covers many more populations than are included by the modern western concept of requiring formal breeder organization and registries. Such undocumented populations are most likely to persist in marginalized situations, and they therefore tend to have high levels of adaptation and genetic uniqueness which are important targets for conservation efforts. These populations are often called landraces, as opposed to the standardized breeds that are usually what springs to mind when "breed" is used to describe an animal population [2]. Strategies for conserving landraces can be easily transferred to standardized breeds that have become rare, although the converse is not true. Therefore targeting procedures for the challenging task of conserving landraces is a useful tactic for all breed conservation. A variety of methods is useful in this process, and these have been used successfully across many species and locations.

\section{Procedures and Methods}

Most landraces persist in areas that are geographically remote or are culturally or economically marginalized. This setting brings with it challenges in effective conservation. Landrace conservation depends on a process that can be broken down into the categories of Discover, Secure, and Sustain [2,7]. Success depends on all three working together, and failure is assured by failure in any one of the three.

Discovery in most situations has historically been haphazard, but increasingly this step is organized with formal efforts to locate landrace populations that are endangered by introgression from animals introduced from breeds novel to the region. Discovery yields candidate populations which must then be assessed for their status as genetic resources (breeds) and also as to their relative priority for conservation. A candidate population's status as a genetic resource usually can be reduced to investigations based on history, phenotypic appearance, and then with DNA or other genetic evaluation as a final step [2,7]. The first two steps (history and phenotype) use fewer resources than the third (DNA investigation) and in cases investigated so far the DNA findings concur with evaluations of history and phenotype when those have revealed significant introgression. The opposite situation is those few populations for which DNA results reject their status as breeds, even though they have successfully passed through evaluations of history and phenotype. This suggests that an economically wise approach is to first eliminate nonqualifying populations based on phenotype and history, which sacrifices minimal accuracy of the final conclusions that can and should be based on results from genetic investigations. Candidate populations that emerge successfully from evaluation 
of history, phenotype, and DNA and can be proven to be distinct and distant from other breeds have an especially high priority for conservation.

Most landraces have a history of a specific foundation event, although often this is cloaked in mystery due to having occurred long ago. The histories of many groups of landraces, such as the Criollo breeds of the Americas, have a collective origin in a limited source (Iberia and Africa in this case) that can help drive assessment and conservation decisions [5]. In the case of limited foundation events, such as is typical of island populations, subsequent genetic drift can further influence the final genome of the population [8].

The history most useful for conservation involves a specific foundation followed by genetic isolation. Isolation allows the population to develop a reasonably uniform genome rather than extremely high levels of variation that are typical of populations with repeated introduction of alien genomes. In many cases the historical investigation becomes controversial because proponents of conservation point to a pristine foundation with no introgression, while detractors usually point to repeated introgression from a wide variety of sources. This divergence is especially typical of controversial populations such as feral livestock for which advocates push for complete conservation in situ while detractors push for eradication [2].

Phenotype can help to settle some questions of foundation and history. The external phenotype accurately betrays the underlying genome in most cases [2]. This is logical, because phenotype does proceed from genotype. Evaluating phenotype across entire populations yields more accurate results than an evaluation based solely on an individual animal, because across populations the effects of either especially advantageous or especially challenging environments tend to cancel out which allows the underlying genome to more fully express itself.

Fairly early in the process of conservation it is necessary to define the target population [9]. This step is rarely present in the unorganized situations that most local breeds or landraces experience. Definition is not all that necessary in situations where isolation is assured from either cultural, geographic, or other factors related to infrastructure, but such situations are increasingly rare worldwide so that defining candidate landrace populations for potential conservation action has taken on greater importance. Conservation increasingly must become deliberate rather than casual, and definition can guide decisions as to which animals to include and which to exclude from conservation programs focused on retention of biodiversity. Definitions should take into account history, local cultural practice, and overall phenotype and genotype of the animals. These all work together to help establish goals for conservation.

Definition works closely with the next step, which is to establish conservation populations. The goal is to include every animal that has a genome typical of the group, and to reject all of those with introgression from other sources. This goal is superficially easy to state, but is actually quite difficult to accomplish in field situations where the simplicity is complicated by cultural and political factors as well as by biological factors such as different degrees of genetic introgression.

One useful method for evaluating animals that are candidates for inclusion into conservation programs is a matrix of phenotypic characteristics [10]. An effective matrix emphasizes characteristics that relate to the relative purity of breeding of the animal, which is different than an assessment of overall breeding quality for production purposes. The matrix should include characteristics that reveal introgression from those external breeds that are most likely to have compromised the integrity of the targeted genetic resource. This often involves conformational details of head, horns, ears, and other somewhat superficial characteristics that are of limited use in production selection but that have great utility in assessing the breed of origin of an animal, and through that, the underlying genome. The phenotypic matrix provides a quick and reliable tool for evaluations of animals in field situations where close access to animals may be difficult or impossible due to lack of handling facilities or animals unused to human contact.

The process of assessing candidate populations can also be aided by analysis of DNA. Results of DNA analysis can serve powerful and useful purposes, and for many observers DNA assessment 
has come to supersede all other evaluations. However, genetic analysis must be put into context not only for its potential strengths but also for weaknesses that can hamper effective outcomes. It is tempting to define local or rare breeds by their DNA profile, because this approach would seem to remove any subjectivity from the process. Unfortunately, the results of DNA analysis very much depend on what goes into the original pool of samples. If specific subpopulations are omitted (either deliberately or inadvertently) from the original analysis then their DNA variants will not be included in the breed profile and these may subsequently come to be viewed as of suspect legitimacy. This is especially important in landraces where subpopulations may be distinct through founder effect, isolation, genetic drift, or selection practices. The question of whether to group these together for conservation or to separate them is important, and must be answered with consideration of the overall chances of long-term successful conservation. In situations where subpopulations are much more like one another than other regional breed resources it generally makes sense to group them together rather than conserving each of them in isolation. In such situations grouping them together more efficiently uses limited resources available for conservation.

A next step in effective conservation is to secure the population [2]. At its most basic level this means avoiding immediate loss of genetic material through loss of animals. A good and complete inventory of animals and their sources is needed in order to organize breeding and maintenance to avoid erosive losses. In some situations this means outright rescue to remove animals from a precarious situation in order to place them in a situation more likely to provide for immediate survival. Rescue must be undertaken carefully. In most situations it is best if animals can remain in their original setting and under their original selection environment. In the case of feral animals and landrace populations owned by elderly, compromised, or deceased individuals, no realistic option other than removal will succeed in securing the population. Rescue situations demand careful attention to breeding decisions in order to maximize retention of genetic variation. In the short term this can often mean that issues of selection for production become secondary to management of genetic variation.

In typical rescue situations involving domesticated animals the population structure is likely to include several more females than males [2]. In this situation the majority of genetic variation resides in the females, and breeding plans must take this into account. A rapid series of matings to the founder females with selective retention of replacement breeding stock from them (and especially the retention of breeding males from these older females) is an effective strategy for maximizing the genetic contribution of the founder females to the descendant population. This effectively maximizes the retention of genetic variation necessary for a secure long-term future for the breed.

The final complicated step is to sustain the population. This requires attention to the genetic structure of the population as well as to selection for production characteristics that will assure long-term use and function for the breed [2]. Breeds that see active use and participation in the market place do not become endangered because it is in the financial interest of owners to keep them viable and productive. Part of the process of sustaining breeds can be to develop demand for the breed and its products. Sustaining breeds also requires attention to the breed's population structure. This, when combined with selection for production characteristics and promotion of the breed and its products, works to secure the breed's place in the agricultural environment in which breeds compete with one another.

\section{Results}

Several experiences with the conservation of landraces illustrate the importance of each of the steps that go into successful conservation efforts. The relative importance of these varies from breed to breed, but each illustrate issues of effective breed conservation. The results of experiences of these steps are best appreciated if discussed along with the results. 


\subsection{American Spanish Goats}

American Spanish goats (Figure 1) derive from a foundation that occurred long ago and was poorly documented. This occurred during the time of Spanish domination of both the southwest and southeastern territory that later became the USA [11]. These goats long served as a local source of goat meat, and were not exposed to much introgression from other breed resources. For most of history goat-meat production was not a main-stream agricultural endeavor in the USA, and as a result American Spanish goats somewhat languished as a local resource used for both meat and brush control. There was basically no incentive to crossbreed them, but that situation changed in the late 1900s with explosion of interest in meat goat production. Two specialized meat goat breeds were imported, the Boer from South Africa and the Kiko from New Zealand. Many breeders began to crossbreed local American Spanish goats to these two imported breeds. The local genetic resource became at risk of extinction through introgression.

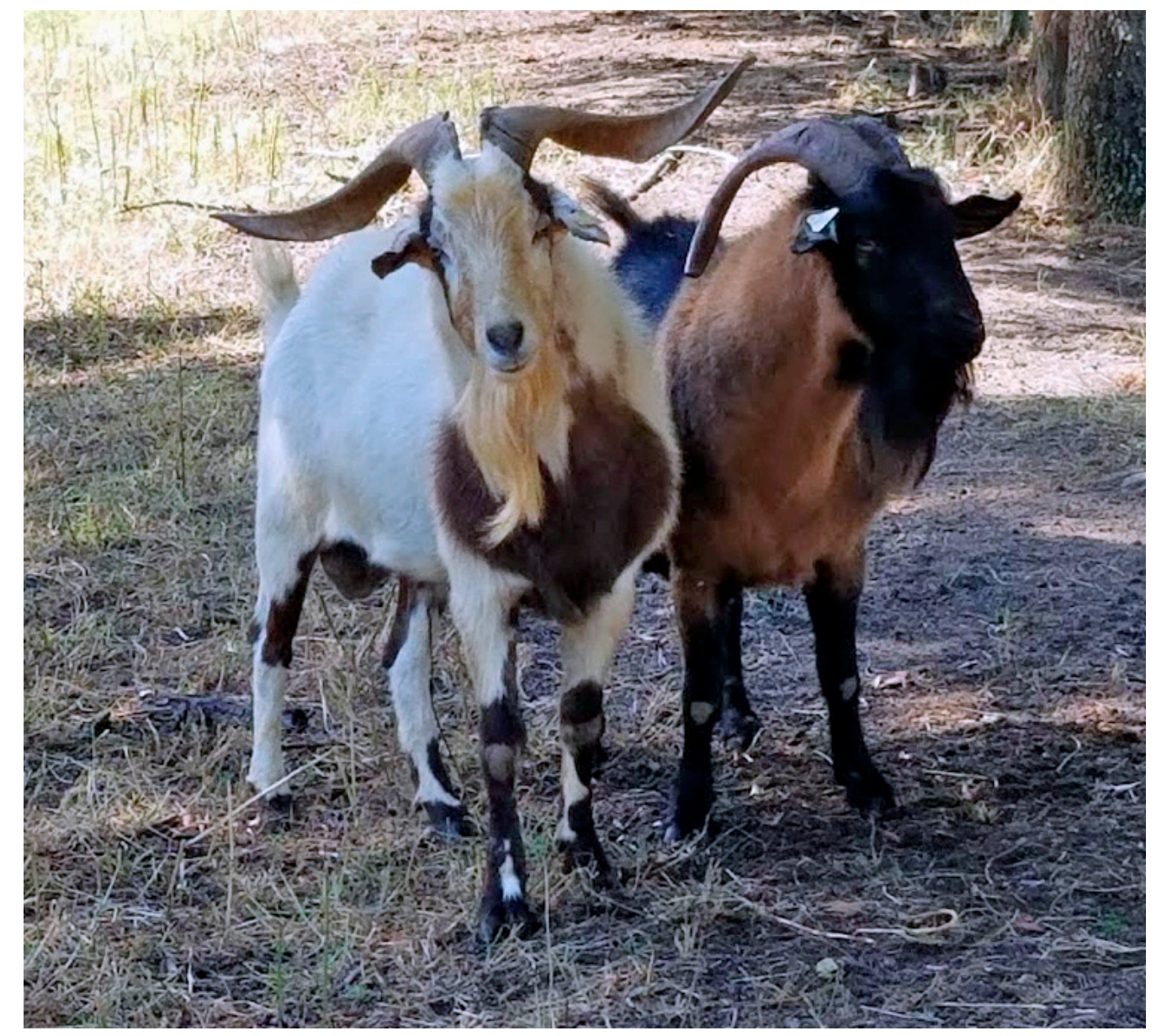

Figure 1. American Spanish goats. Mature bucks. Photo by D. Askew.

Efforts at conservation targeted an accurate census based on external phenotypic evaluation in herds with a history of isolation. In this case, the matrix used for evaluation was based on conformational details most likely to be changed by crossbreeding to other available resources: Swiss dairy, Nubian, Angora, Boer, and Kiko. The final result was successful location of several thousand goats that fit the description of the American Spanish goat, with the disadvantage that many of these were in herds of over 1000. The significance of large herds is that despite a relatively high census the risk of loss remains high because decisions by very few people could place the breed at grave risk of loss. Breeders loosely organized an information network that provided a way for new breeders to access 
typical stock that is free of introgression. Recent developments include a more formal breed association, with a registry process for individual goats likely to be developed. Both a formal association as well as a registry can work to assure breeding of goats that are within the typical genome, but also have an unintended consequence of closing the breed either formally or informally. This becomes a barrier to inclusion of newly-encountered herds, and such herds are likely to be encountered for several decades with landraces such as the American Spanish goat.

Once the breed was defined and described, it was possible to do DNA evaluation across several of the founding lines of the breed [8,12]. The results of this effort validated the fact that this external phenotype, which is spread throughout the Americas, shares the genetic evidence expected of a common foundation centuries ago. Validation and definition of the American Spanish goat as a local breed resource aided researchers in adding this breed to multi-breed comparisons, with the encouraging result that this locally developed landrace offers real advantages over the more popular recently imported breeds. Documentation of the productive potential has secured the breed a place in production agriculture, leading to further security against nondeliberate genetic erosion $[13,14]$.

A few bloodlines, especially from the southeastern region that is humid subtropical, had dwindled to only a few representatives. One of these, from Florida, had been on the property for the whole history of the enterprise, and had numbered in the high hundreds of individuals. The owners then decided to eliminate goats from their production system, and by the time the conservation community was alerted to the situation the numbers had declined to only six does. They were pregnant to the last buck that had been sold, and fortunately photographs showed him to be typical of the breed in every way. The kids from this original foundation included both males and females, and the males were then used back in different combinations on the original females in order to minimize the effects of a genetic bottleneck. This strategy will be repeated until the original females are no longer available for reproduction, which will assure that this bloodline with its adaptation to humid conditions will remain available to contribute to the overall breed.

American Spanish goat conservation illustrates the importance of a good breed definition, as well as the utility of a phenotypic matrix in evaluating candidate animals for inclusion or exclusion into conservation programs. The trajectory of a landrace becoming a more main-stream production breed brings with it future challenges, and how there are met is yet to be fully determined. In addition, rare bloodlines are still surfacing to the attention of the conservation community, and these are each the target of rescue protocols to minimize the loss of their contribution to the breed's genetic diversity.

\subsection{Texas Longhorn Cattle}

Texas Longhorn cattle (Figure 2) illustrate the importance of a good breed definition [15]. The original foundation of this breed is from cattle introduced by the Spanish. Texas Longhorns share that heritage with numerous breeds from this origin, generally referred to as "Criollo." Interest in organizing and saving this breed goes back to the early 1900s but became more popular in the 1960s and 1970s. At that time the prevailing attitude was to include most cattle with long horns that came from Texas. A few breeders became disheartened at the inclusion of cattle with obvious introgression of British, recent African, or Zebu breeding. The breed definition used by this later group of conservation-minded breeders was Iberian cattle, with long horns, in Texas. This is a more restrictive definition but also focuses on a unique genetic origin distinct from other breed resources available in the area, which is a major factor in effective landrace conservation and use.

Early efforts by this group focused on assembling qualifying cattle into conservation herds, and this involved inspection for external phenotype followed by blood-typing. These two worked well in concert, with only a very few animals qualifying by phenotype but then later rejected by bloodtyping. Technological developments have led to bloodtyping (based on protein antigens) to be replaced by DNA analysis, generally by microsatellites but moving in the direction of SNP or sequencing data. These techniques do not yield equivalent information, but are being used in largely the same way as bloodtyping was. 


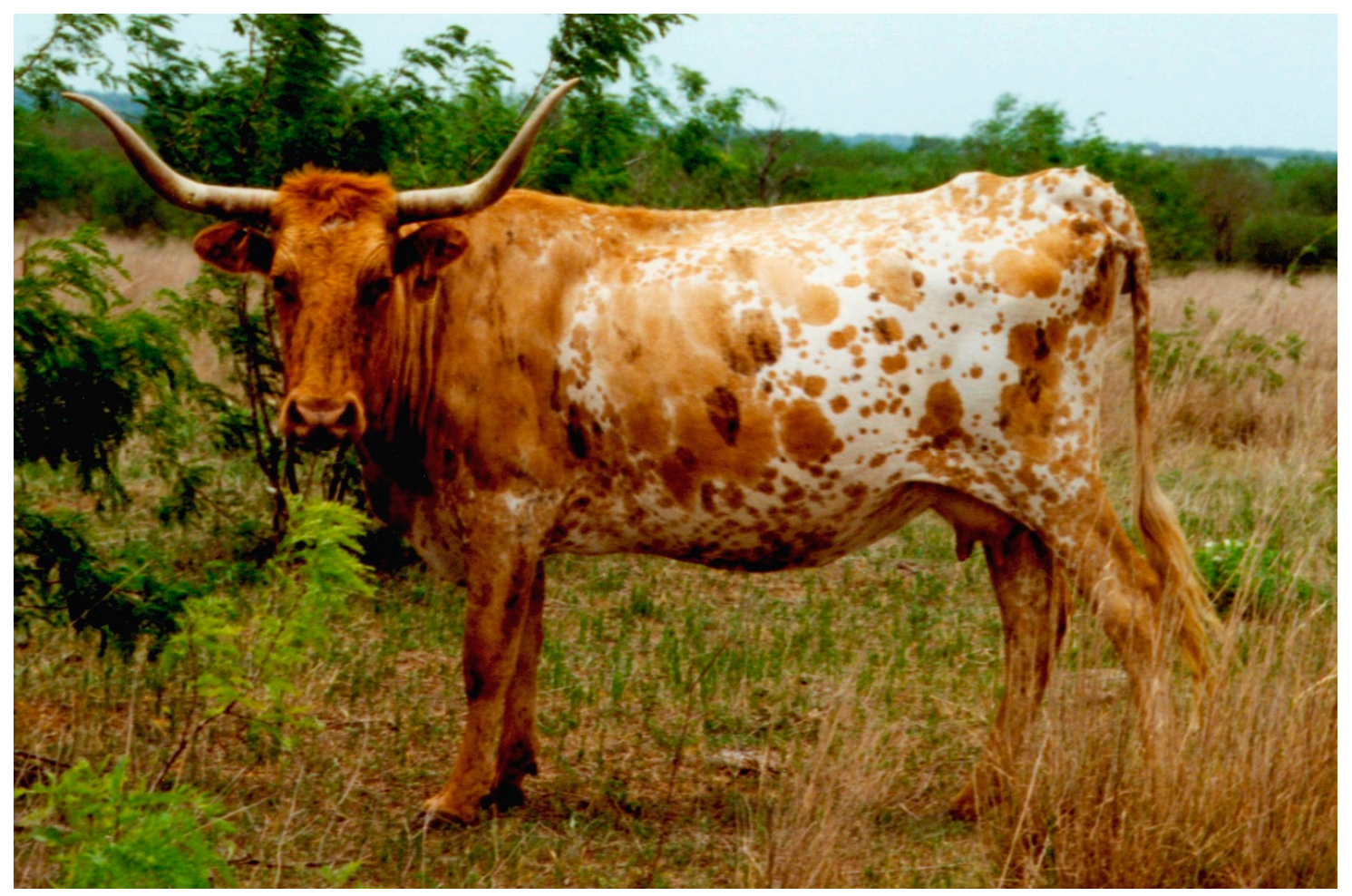

Figure 2. Texas Longhorn cow of traditional criollo type. Photo by D.P. Sponenberg.

The importance of the Iberian origin for the breed is that this branch of cattle is quite distinct from British, Northern European, and Indian (Zebu) cattle [5]. They are therefore a high priority for effective conservation and wise use, but only if kept distinct from these other influences

Results of DNA analysis have proven the wisdom of the more strict definition [5]. Multiple studies have shown the uniqueness of the breed. One study initially had the Texas Longhorn branching off close to the Hereford (British) but when the investigators were alerted to the fact that one family had a documented introgression from Hereford, they were able to remove that family and the Texas Longhorn then branched off where expected of Iberian-based Criollo breeds. This validates that a good breed definition can drive conservation and secure unique genetic resources for the future. Later studies have demonstrated the close relationship of the Texas Longhorn to other breeds of similar foundation in the Americas. The presence in these breeds of a preponderance of a genetic influence that is now rare in other areas of the world points to the need to document these local breeds and then to effectively conserve them.

Genetic studies have also revealed zebu introgression into some bloodlines of Texas Longhorns through analysis of the male-specific genome inherited with the $Y$ chromosome. These results aided breeders in eliminating zebu influences from those populations of most concern in the conservation of the Texas Longhorn as an example of an Iberian-based Criollo breed.

\subsection{Navajo-Churro sheep}

Navajo Churro sheep (Figure 3) offer a similar success of phenotypic evaluation leading to effective conservation [16]. In this case the unique aspects of the fleece are highly desired for traditional textiles, which affords the breed a commercial utility. Navajo-Churro breeders have opted for a relatively open breed registry, but with the insistence that each animal qualify for inclusion by virtue of its own phenotype that is evaluated by an inspection either on-site or by photographs. This has broadened the geographic range of the breed beyond its original location, which is a good strategy for minimizing the risk of loss to a localized disaster. Breeders of Navajo-Churro sheep are careful to document various aspects of phenotype such as color and the presence and number of horns. When specific characters 
become rare, breeder are alerted and many of them then retain more of that phenotype so that no phenotypic variant risks inadvertent extinction. This is a relatively informal way to assure that the breed's genetic variation does not diminish over time.

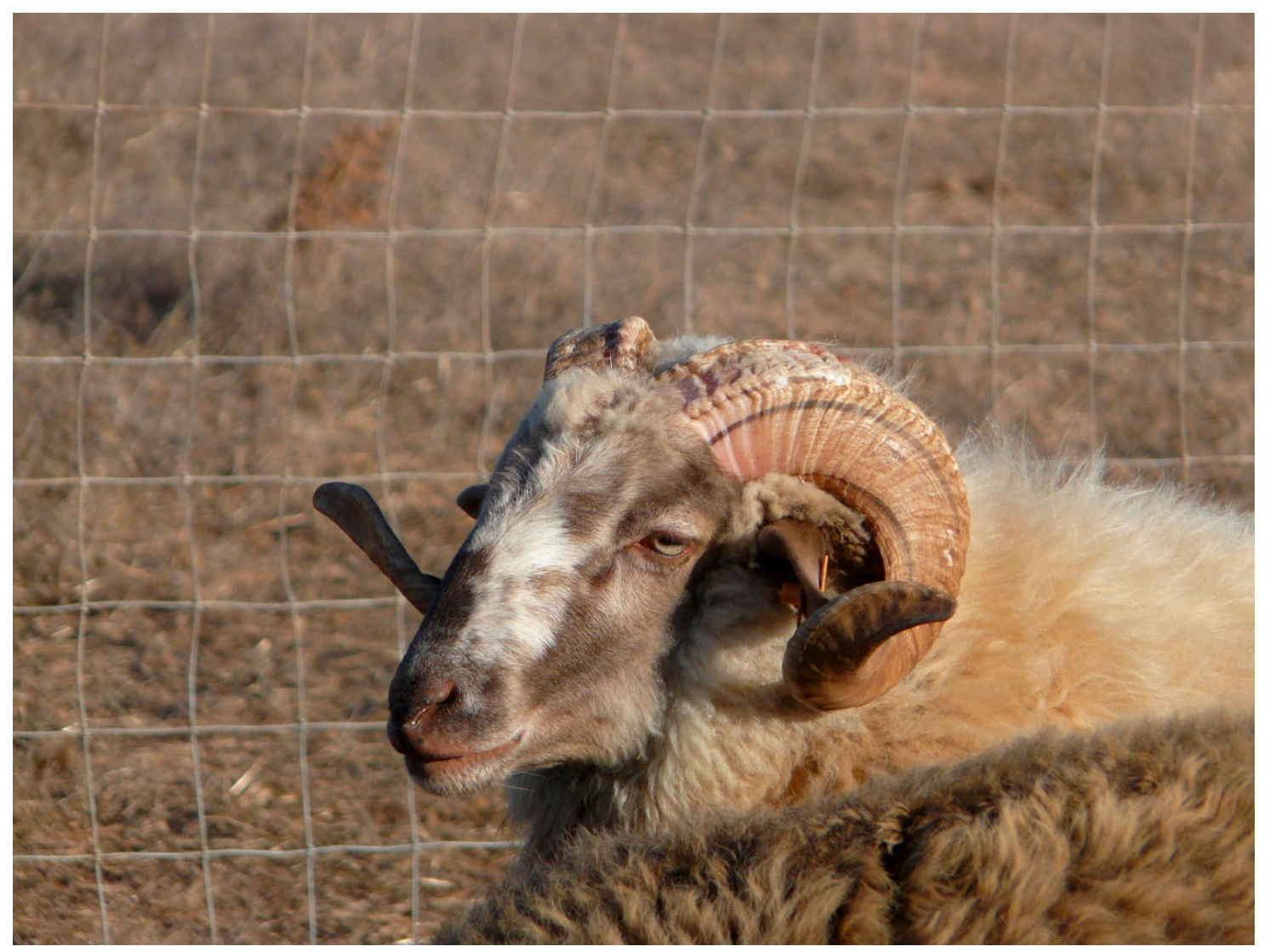

Figure 3. Navajo-Churro ram. Photo by D.P. Sponenberg.

\subsection{Pineywoods Cattle}

In most cases the definition and organization of the landrace requires attention to the very real aspects of enhancing long-term potential for successful conservation. In the case of Pineywoods cattle from the Gulf Coast region (Figure 4), the breed once ranged extensively in herds of thousands [2,15,17]. Over the last century the numbers contracted due to breed replacement as well as by introgression from introduced breeds. The end result of this process was several herds, each isolated from the others by up to a century. In this situation each of these herds could easily be considered to be its own unique breed. The overlying issue was that the type of animal in each herd was much more like one another than they were to any other breed resource in the area. By combining these herds of similar phenotype (despite their long-term isolation) it became much more possible to adequately conserve the genetic variation present and to use limited resources for conservation much more effectively than had they been split among several different and numerically smaller breeds that would each have faced the risk of decline from inbreeding depression.

Pineywoods cattle also illustrate one of the challenges of landrace conservation, which is the fact that a complete inventory of animals is rarely if ever possible. From time to time new candidate herds emerge, or individual cattle from previously documented herds that have fallen from notice. It is important for breed organizations to remain open to including such animals, following rigorous investigations into the validity of the claims that such animals are indeed Pineywoods cattle. In the case of Pineywoods cattle, the history of long-isolated herds of cattle has had the consequence that foundation events and genetic drift have worked to blur cohesive DNA fingerprints when compared to 
other criollo breeds in the Americas [5]. The breed remains distinct from other extant breed resources in its home tract, but this situation does complicate iron-clad validation of candidate animals through DNA evaluation, and in this situation history and phenotypic evaluation become relatively more important. Herd books in Europe provide for the rescue of animals into complementary registers, which helps to assure that these animals are not completely lost to their breeds.

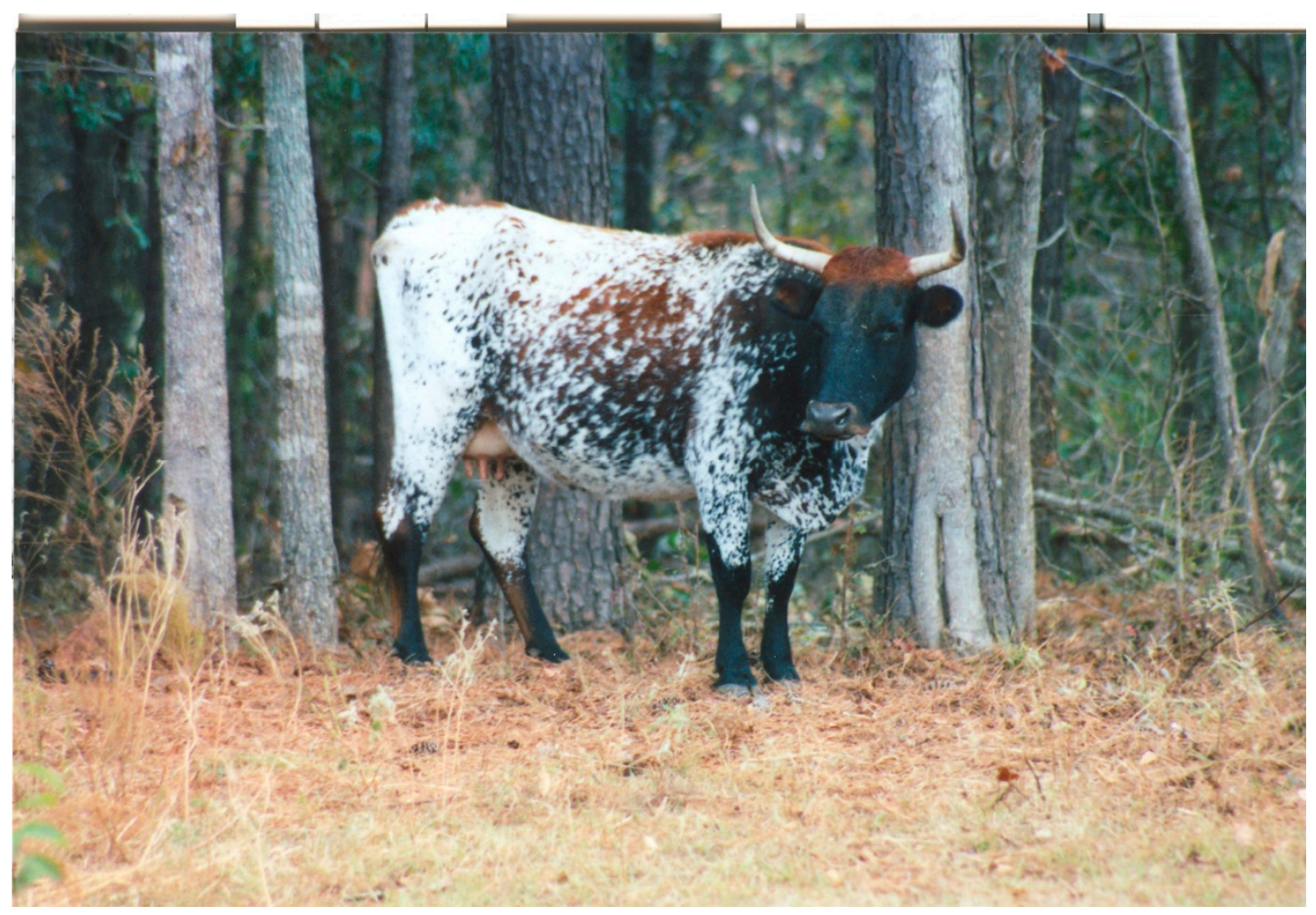

Figure 4. Pineywoods cow of the Conway line, with a variation from Virgil Berry's herd. Photo by D.P. Sponenberg.

\subsection{Randall Lineback Cattle}

Randall Lineback cattle (Figure 5) are a remnant of a once-common local breed type from the northeast of the United States [18]. These cattle have long been recorded in historical documents, but early efforts at breed organization included only one attempt at forming the Columbia cattle breed in New York and adjacent states. Linebacked cattle did persist in the region until the late 1900s, but were increasingly crossbred to Holstein bulls in an effort to enhance the milk production characteristics of this originally triple-purpose breed type.

In the 1980s only a single herd was found to persist, and upon the death of the owner the herd was dispersed, to be rescued by a handful of dedicated breeders. The history of the herd, in common with many other rare breeds, was one of retention of bulls for long breeding careers. Over several generations this strategy greatly diminishes genetic variation because bulls are increasingly mated to their half-sisters or their own daughters. Randall Lineback cattle descend from only 12 founders that all originate from this single herd with a history of a genetic bottleneck imposed by this breeding strategy.

Validation and breeding efforts began with the founders, all of which were interrelated but exact relationships were undocumented other than the inferred conclusion that animals of a single birth year cohort were half-siblings. Breeding strategies were put into place with two different goals. One goal was to line breed back to specific individual founders in order to enhance distance from other animals. A second goal was to cross among these to balance founder contributions while reducing inbreeding 
coefficients. A strategy to facilitate maintenance of genetic diversity was to use bulls for only a year or two, rather than the traditional multi-year breeding career that collapsed genetic diversity.

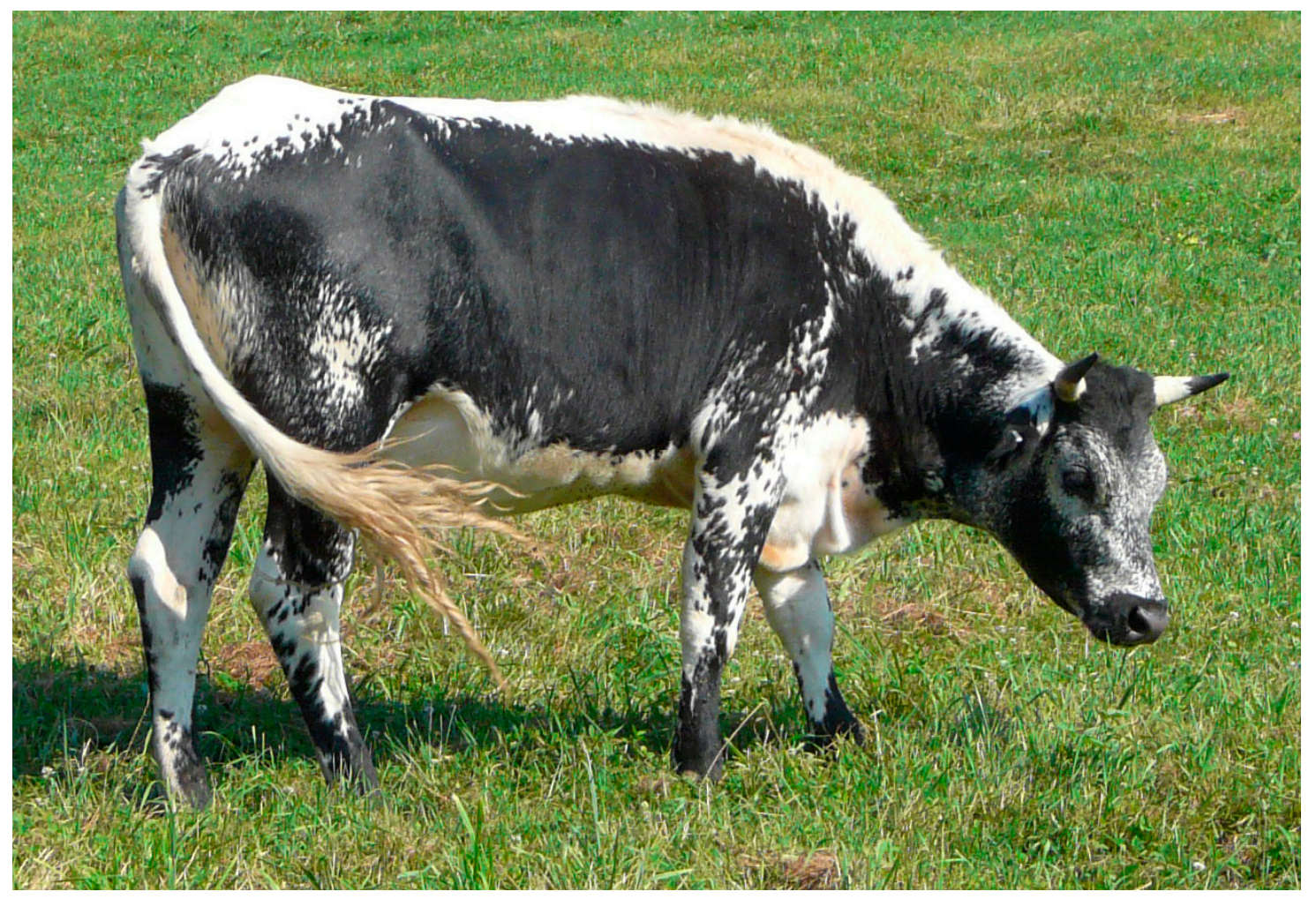

Figure 5. Randall Lineback cattle are a New England landrace. Photo by D.P. Sponenberg.

The breed expanded to about 500 head by 2015, only due to the persistence of conservation breeders. The breed faced diminished reproductive efficiency, such that calving rates of only $50 \%$ were typical of some herds. Other herds, through selection and good husbandry, have raised this up to $95 \%$, assuring the breed a place in productive cattle systems.

Another challenge faced by the breed was diminished cooperation among breeders, some of whom had become competitors rather than cooperators. In this split, pedigrees became suspect in some herds, with some breeders casting aspersion on the purity of the cattle of others. Fortunately DNA studies based on microsatellites revealed low variability at most loci, in keeping with the breed's history of isolation and sequential use of single bulls per generation. The low levels of genetic variation provide for detection of any crossbred cattle, a few of which were known and included in the study for comparison to those known to only descend from the Randall Lineback foundation herd. The results were useful in validating the history and status of the breed, but also in allowing conservators to be sure of the purity of animals despite the lack of accurate pedigrees for some individual animals.

The Randall Lineback is a good example of the perils of long-term isolation of small populations in reducing genetic variability and the associated risk of reducing levels of production from inbreeding depression. It is also a good example of the consequences of diligent selection in maintaining and enhancing productive potential. The breed also illustrates the hazards of poor cooperation among breeders of rare breeds, where individual breeder choices can have adverse effects on population structure and numbers.

\subsection{Heritage Turkeys}

Heritage turkeys (Figure 6) are non-industrial varieties of turkeys that have long seen use in sustainable extensive production systems that depend on natural mating and natural incubation [19]. 
These turkeys face long-term challenges from the vertical integration of the turkey industry which is able to provide high-quality protein with low retail prices.

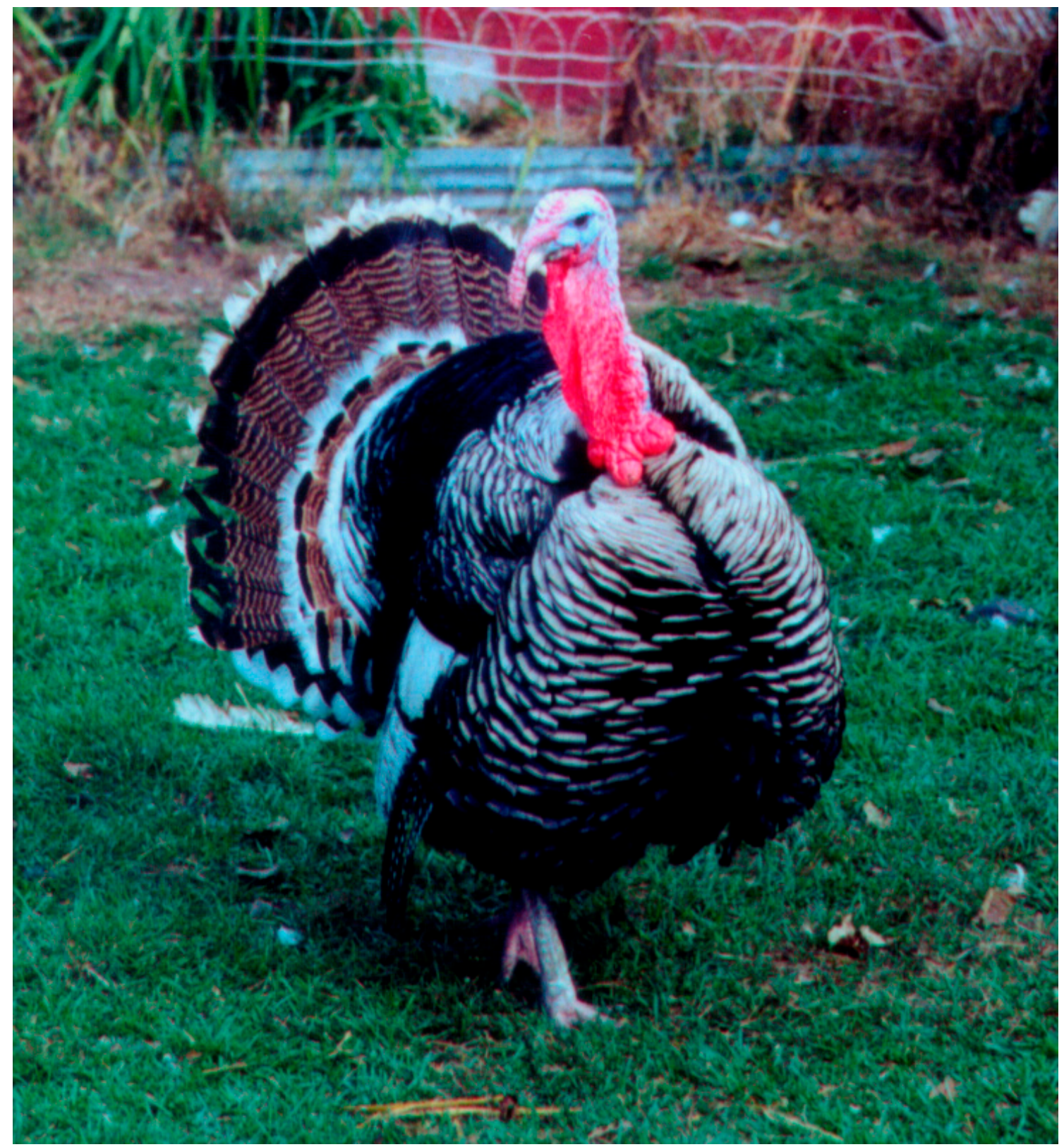

Figure 6. Heritage turkey of the Narragansett variety. Photo by D.P. Sponenberg.

By the late 1980s the numbers of breeding birds of non-industrial heritage turkeys had plummeted. This occurred mostly due to diminished appreciation of non-industrial systems for turkey production as well as the birds that fit into that system. The key to reversing this trend was to enhance demand for heritage turkeys. This hinged on the presence in the USA of a national holiday, Thanksgiving Day, that occurs at the end of November and tends to be one of the few holidays that unites Americans into a national identity that is free of sectarian overtones.

Linking the heritage turkey with this holiday was able to enhance demand for a product that is elite and different from the industrial birds. This linkage, up to now, has been relatively informal without any specific labelling or other official differentiation of the product other than the efforts of individual producers communicating locally with their customers. Despite this rather low-level approach, the demand generated by this effort has increased the production of heritage varieties by 
about ten times over the level in 1980, which has assured that hatcheries and other producers of these turkeys were able to keep populations at levels that allow for viability as well as ongoing selection for productivity. Creating demand has been essential in assuring that producers have kept these distinctive varieties ongoing.

As a consequence of the decline in both bird numbers and bird producers in the late 1900s many of the traditional techniques for selection and maintenance were at risk of being lost. This cultural loss is one of the long-term effects of breed endangerment as the numbers of people familiar with their production decline. In this case the Livestock Conservancy was able to recapture many of these techniques and to provide them to new generations of producers through a series of educational symposia and hands-on experiences guiding these newly engaged advocates through the subtle details of breeder bird selection and management.

\subsection{Santa Cruz Island Sheep}

Santa Cruz Island sheep are a feral sheep population from an island off the coast of California [20,21]. Their history is fairly typical of feral livestock in the USA, especially those on islands. In this situation the degradation of natural ecosystems takes priority over the biodiversity within the feral population, with feral animals slated for removal. This is often accomplished by killing the feral animals, but in this and other situations conservation interests have allowed for the live capture and removal of sufficient animals to establish $e x$ situ populations that persist in domestic, managed situations. While these cannot ever duplicate the intricacies of selection under natural conditions, they do conserve some level of genetic diversity that would otherwise be lost.

Finding a productive role for livestock populations that were once feral is challenging, because their selection environment has usually produced a minimally-productive (if exquisitely adapted) genotype and phenotype. In the case of the Santa Cruz Island sheep it has been possible to increase demand for their wool, for use by handspinners. This has been done by a successful program of the Livestock Conservancy aimed at all breeds of heritage sheep. The program is "Shave 'Em to Save 'Em" and connects producers of rare-breed wools with artisans interested in using these wools to create unique products [22]. The program involves enlisting producers of raw or processed fleece, and provides them with breed-specific stickers that then accompany product (fleece, roving, or yarn in most cases) to end-users. Those end-users are provided with a "passport" that includes a page for each breed, and they are then able to apply those stickers to the appropriate page. Incentives are in place to reward artisans who use wools from $5,10,15$, or more rare breeds.

\section{Conclusions}

Effective breed conservation depends on attention to biological, genetic, and cultural factors, failure in any of which can lead to overall failure. Effective landrace conservation is especially challenging because the target populations are usually poorly defined at the outset of conservation efforts. The practical approach of Discover, Secure, and Sustain has worked for several landrace populations in the USA, and results in conservation priorities in a manner that uses limited resources wisely. This approach relies on local cultural and historical knowledge, which gives it the advantage of being easily transferred to situations outside of North America. The wisdom of using an approach that addresses historic and phenotypic evaluations early in the process, to be followed by DNA analysis later, has been validated for several populations and promises to serve well in the future.

Author Contributions: Conceptualization, D.P.S. and A.M.; methodology, D.P.S., A.M., C.C., and J.B.; investigation, D.P.S, J.B.; writing—original draft preparation, D.P.S.; writing—review and editing, A.M., C.C., J.B.

Funding: This research received no external funding.

Conflicts of Interest: The authors declare no conflict of interest. 


\section{References}

1. Francis, R.C. Domesticated; W. W. Norton \& Company: New York, NY, USA, 2015; pp. 1-320.

2. Sponenberg, D.P.; Martin, A.; Beranger, J. Managing Breeds for a Secure Future, Strategies for Breeders and Breed Associations, 2nd ed.; 5M Publishing: Sheffield, UK, 2017; pp. 1-288.

3. The Food and Agriculture Organization. In Vivo Conservation of Animal Genetic Resources; FAO Animal Production and Health Guidelines: Rome, Italy, 2013; pp. 1-242.

4. Ramljak, J.; Bunevski, G.; Bytyqi, H.; Marković, B.; Brka, M.; Ivanković, A.; Kume, K.; Stojanović, S.; Nikolov, V.; Simčič, M.; et al. Conservation of a domestic metapopulation structured into related and partley admixed strains. Mol. Ecol. 2018, 27, 1633-1650. [CrossRef] [PubMed]

5. Ginja, C.; Gama, L.T.; Cortés, O.; Martin Burriel, I.; Vega-Pla, J.L.; Penedo, C.; Sponenberg, P.; Cañón, J.; Sanz, A.; Egito, A.; et al. The genetic ancestry of American Creole cattle inferred from uniparental and autosomal genetic markers. Sci. Rep. 2019, 9, 11486. [CrossRef] [PubMed]

6. Castañeda, C.; Juras, R.; Khanshour, A.; Randlaht, I.; Wallner, B.; Rigler, D.; Lindgren, G.; Raudsepp, T.; Cothran, E.G. Population Genetic Analysis of the Estonian Native Horse Suggests Diverse and Distinct Genetics, Ancient Origin, and Contribution from Unique Patrilines. Genes. 2019, 10, 629.

7. Sponenberg, D.P.; Beranger, A.M.; Martin, C.R. Couch. Conservation of Rare and Local Breeds of Livestock and Poultry. Sci. Tech. Rev. 2018, 37, 259-267. [CrossRef] [PubMed]

8. Sevane, N.; Cortés, O.; Gama, L.T.; Martínez, A.; Zaragoza, P.; Amills, M.; Bedotti, D.O.; Bruno de Sousa, C.; Cañon, J.; Dunner, S.; et al. Dissection of ancestral genetic contributions to Creole goat populations. Animal 2018, 12, 2017-2026. [CrossRef] [PubMed]

9. Sponenberg, D.P.; Quiroz, J. Definición de Razas Locales-Primer Paso en su Conservación. AICA 2017, 10, 74-77.

10. Sponenberg, D.P.; Reed, C. Uso de Matrices Fenotípicos en la Conservación de Razas Locales. AICA 2015, 6, 67-73.

11. Sponenberg, D.P.; Edmundson, L. Razas Caprinas y Locales en Los Estados Unidos (Criollo and Local Goat Breeds in the USA). In Biodiversidad Caprina Iberoamericana; Vargas, J.E., Zaragoza, L., Delgado, J.V., Rodríguez, L., Eds.; University of Córdoba: Córdoba, Spain, 2016; pp. 154-170.

12. Ginja, C.; Gama, L.T.; Martínez, A.; Sevane, N.; Martín-Burriel, I.; Lanari, M.R.; Revidatti, M.A.; Aranguren-Méndez, J.A.; Bedotti, D.O.; Ribeiro, M.N.; et al. Genetic diversity and patterns of population structure in Creole goats from the Americas. Anim. Genet. 2017, 48, 315-329. [CrossRef] [PubMed]

13. Browning, R.; Leite-Browning, M.L. Birth to weaning kid traits from a complete diallel of Boer, Kiko, and Spanish meat goat breeds semi-extensively managed on humid subtropical pasture. J. Anim. Sci. 2011, 89, 2696-2707. [CrossRef] [PubMed]

14. Browning, R.; Leite-Browning, M.L.; Byars, M. Reproductive and health traits among Boer, Kiko, and Spanish meat goatts on humid, subtropical pasture conditions of the southeastern United States. J. Anim. Sci. 2011, 89, 648-660. [CrossRef] [PubMed]

15. Sponenberg, D.P.; Davis, D.; Beranger, J. Catálogo de los Bovinos Criollos de México: Razas Locales y Sistemas Empéricos de Manejo; Universidad Autónoma de Chiapas: San Cristobal de las Casas, Mexico, 2018.

16. Taylor, C.; Sponenberg, D.P.; Perezgrovas, R. Biodiversidad Ovino Iberoamericano; Universidad de Córdoba: Córdoba, Spain, 2010; pp. 447-462.

17. Sponenberg, D.P.; Oxborrow, T.; Gómez, M. La raza bovina Pineywoods (The Pineywoods cattle breed). Arch. Zootec. 2005, 54, 245-251.

18. Sponenberg, D.P.; Creech, C.; Miller, W.J. Randall Cattle in the USA: Rescuing a genetic resource from extinction. Anim. Genet. Resour. 2007, 41, 9-16. [CrossRef]

19. Sponenberg, D.P.; Bender, M.; Johnson, P.; Smith, E.; Gogal, R.; Pierson, F.W.; Gómez Jaramillo, M.A. La conservación del pavo en los Estados Unidos (Turkey conservation in the United States). Arch. Zootec. 2005, 206, 177-183.

20. Van Vuren, D.; Coblenz, B.E. Population Characteristics of Feral Sheep on Santa Cruz Island. J. Wildl. Manag. 1989, 53, 306-313. [CrossRef] 
21. Martin, A. Rescue of Santa Cruz Island Sheep - An Early Success. Livest. Conservancy News 2014, 31, 1-10.

22. Livestock Conservancy. Shave 'Em to Save 'Em. Livest. Conservancy News 2010, 36, 1-4.

(C) 2019 by the authors. Licensee MDPI, Basel, Switzerland. This article is an open access article distributed under the terms and conditions of the Creative Commons Attribution (CC BY) license (http://creativecommons.org/licenses/by/4.0/). 